\title{
Development and measurement properties of the AxEL (attitude toward education and advice for low-back-pain) questionnaire
}

Edel T. O'Hagan ${ }^{1,2^{*}}\left(\mathbb{0}\right.$, Ian W. Skinner ${ }^{3}$, Matthew D. Jones $^{1,4}$, Emma L. Karran ${ }^{5}$, Adrian C. Traeger $^{6}$, Aidan G. Cashin ${ }^{1,4}$, Benedict M. Wand', Siobhan M. Schabrun' ${ }^{1}$, Sean O'Neill ${ }^{8,9}$, Ian A. Harris ${ }^{6,8,10}$ and James H. McAuley ${ }^{1,4}$

\begin{abstract}
Introduction: Clinician time and resources may be underutilised if the treatment they offer does not match patient expectations and attitudes. We developed a questionnaire (AxEL-Q) to guide clinicians toward elements of first-line care that are pertinent to their patients with low back pain.

Methods: We used guidance from the COSMIN consortium to develop the questionnaire and evaluated it in a sample of people with low back pain of any duration. Participants were recruited from the community, were over 18 years and fluent in English. Statements that represented first-line care were identified. Semantic scales were used to measure attitude towards these statements. These items were combined to develop the questionnaire draft. Construct validity was evaluated with exploratory factor analysis and hypotheses testing, comparing to the Back Beliefs Questionnaire and modified Pain Self-Efficacy Questionnaire. Reliability was evaluated and floor and ceiling effects calculated.

Results: We recruited 345 participants, and had complete data for analysis for 313 participants. The questionnaire draft was reduced to a 3-Factor questionnaire through exploratory factor analysis. Factor 1 comprised 9 items and evaluated Attitude toward staying active, Factor 2 comprised 4 items and evaluated Attitude toward low back pain being rarely caused by a serious health problem, Factor 3 comprised 4 items and evaluated Attitude toward not needing to know the cause of back pain to manage it effectively. There was a strong inverse association between each factor and the Back Beliefs Questionnaire and a moderate positive association with the modified Pain Self-Efficacy Questionnaire. Each independent factor demonstrated acceptable internal consistency; Cronbach a Factor $1=0.92$, Factor $2=0.91$, Factor $3=0.90$ and adequate interclass correlation coefficients; Factor $1=0.71$, Factor $2=0.73$, Factor $3=0.79$.
\end{abstract}

Conclusion: This study demonstrates acceptable construct validity and reliability of the AxEL-Q, providing clinicians with an insight into the likelihood of patients following first-line care at the outset.

Keywords: Low back pain, Questionnaire development, Measurement properties, First-line care

*Correspondence: e.ohagan@neura.edu.au

${ }^{1}$ Centre for Pain IMPACT, Neuroscience Research Australia (NeuRA), 139 Barker Street, Randwick, NSW 2031, Australia

Full list of author information is available at the end of the article

\section{Introduction}

Low back pain is the leading contributor to the global disability burden [1]. Between 1990 and 2019, low back pain caused one of the largest absolute increases in the number of days lost to disability of any health condition, and this upward trajectory is predicted to continue, original author(s) and the source, provide a link to the Creative Commons licence, and indicate if changes were made. The images or other third party material in this article are included in the article's Creative Commons licence, unless indicated otherwise in a credit line to the material. If material is not included in the article's Creative Commons licence and your intended use is not permitted by statutory regulation or exceeds the permitted use, you will need to obtain permission directly from the copyright holder. To view a copy of this licence, visit http://creativecommons.org/licenses/by/4.0/. The Creative Commons Public Domain Dedication waiver (http://creativeco mmons.org/publicdomain/zero/1.0/) applies to the data made available in this article, unless otherwise stated in a credit line to the data. 
exacerbating demands on health systems [2]. Clinical practice guidelines for the management of low back pain consistently recommend that first-line care should include advice, education and reassurance to minimise unnecessary interventions and decrease the burden on health systems [3, 4]. Regardless of the duration of low back pain, clinicians should provide advice to remain active, education on the benign nature of low back pain, and reassurance about the absence of a serious medical condition [5-7].

Systematic reviews have highlighted the gap between clinical practice guideline recommendations for first-line care and the care that is usually provided to people with low back pain $[8,9]$. The suboptimal use of first-line care is influenced by both clinician and patient-related factors [10]. For example, clinicians often report insufficient time and resources to appropriately provide first-line care within the time constraints of an initial consultation [11]. For patients, adherence to first-line care is influenced by their expectations for treatment and attitudes towards the specific health care behaviour [12, 13]. A greater understanding of patient attitudes toward first-line care could assist clinicians in providing more efficient and effective consultations within the time constraints of clinical practice. Clinicians could personalise the care provided to ensure that it aligns with the patient's attitudes and expectations which may improve patient satisfaction, better facilitate delivery of first-line care, and potentially improve treatment outcomes [10].

A questionnaire to assess patient attitudes toward firstline care for low back pain could provide clinicians with valuable insight to indicate which components of firstline care people with low back pain are likely to engage with. Questionnaires to measure attitude in people with pain are available but have notable shortcomings. Common limitations include only measuring one component of attitude and having a sizable participant burden. For example, the Pain and Impairment Relationship Scale assesses beliefs and attitudes associated with the experience of chronic pain and one's ability to function despite pain. Attitude and beliefs are measured using a series of 15 agree/disagree questions only [14]. Similarly, the Survey of Pain Attitudes questionnaire assesses 7 painrelated beliefs. Participants indicate their agreement level with 57 statements about low back pain on a 5-point Likert scale, ranging from true or false, with intermediate labels, possibly false, unsure, possibly true [15]. The Back Pain Attitude Questionnaire also requires participants to rate their agreement level with statements on a 5-point Likert scale [16]. Evaluation of the measurement properties suggest that each of these questionnaires demonstrate adequate internal consistency, test re-test stability and hypothesis testing support the convergent and discriminant validity [14-18]. Despite the individual merit of each of these questionnaires, currently there is no reliable method to understand patient attitudes toward first-line care for low back pain, and so valuable clinician time and resources may be underutilised or misdirected when providing first-line care.

Recently a panel of expert researchers and clinicians joined with consumers to compile a list of evidence-based "essential key messages" that the public should know about low back pain [19]. The resulting list included messages about first-line care. We developed a questionnaire to measure attitudes toward those messages that could help clinicians tailor their advice to patients. For example, a negative attitude toward a message of education on the benign nature of low back pain could lead a clinician to discuss that message. Whereas a positive attitude toward a message about advice to stay active would indicate to the clinician may not have to spend time reenforcing that message. To be useful such a tool should demonstrate reliability and construct validity.

This study aimed to.

(i) Develop a new patient-reported questionnaire, the Attitude toward Education and advice for Low back pain-Questionnaire (AxEL-Q).

(ii) Evaluate the construct validity and reliability of the AxEL-Q

\section{Methods}

This study describes the development and evaluation of a questionnaire to assess patient attitudes toward first-line care for low back pain. The process is outlined in Fig. 1. We used the COSMIN consortium developed study design checklist $[20,21]$, guidelines on terminology [22], and risk of bias checklist for clinimetric studies [23] in designing and reporting this study. This study was approved by the University of New South Wales Human Research Ethics Committee prior to data collection (approval number 17919). The protocol was pre-registered on the Open Science Framework in August 2018. (https://osf.io/9wncz/).

\section{Conceptual framework}

The AxEL-Q is based on a reflective model where all items are presumed to measure the same underlying construct, i.e., attitude toward first-line care for low back pain. Attitude toward first-line care for low back pain is a multi-dimensional construct measured indirectly using multiple observable items. The corresponding measurement theory is Classical Test Theory where the observed score of an item is the 'true' score of the construct to be measured plus the error term for that item [24]. 
Attitude

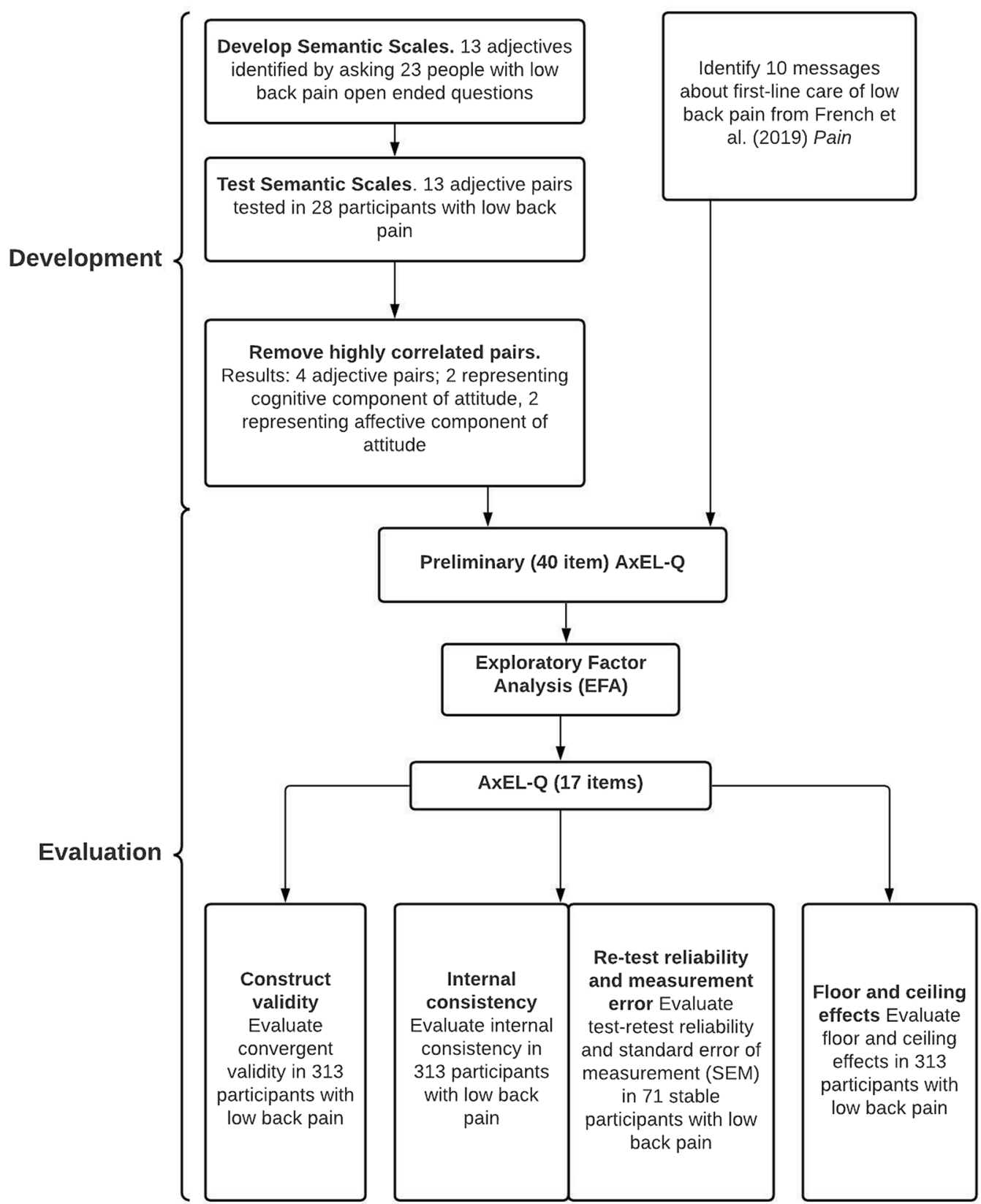

Fig. 1 Development and evaluation of the AxEL-Q

\section{Development of the preliminary AxEL-Q Source population}

We developed the preliminary questionnaire in two independent samples of people with low back pain. Participants were recruited consecutively from databases of people who expressed an interest in research. Participants had low back pain of any duration; all were in
Australia and fluent in English. Participants ranged in age from 18 to 70 years.

\section{Item identification}

Attitude Attitude comprises affective components relating to feelings and emotions and cognitive components relating to thoughts and beliefs [25]. Measuring attitude 
should incorporate both affective and cognitive components. The affective component is evaluative, and because attitudes are always evaluating an object, there is inevitably a cognitive component to represent the object of thought [26]. We used semantic differential scales, which are considered appropriate to measure attitude [27]. Semantic differential scales measure responses in terms of ratings on bipolar scales defined with contrasting adjectives at each end [28].

First-line care A Delphi study [19] identified 30 messages considered important for the public to know about diagnosis, imaging, and self-care for people with low back pain. These 30 messages covered six themes; red flag identification, disease knowledge, reassurance, stay active, unnecessary interventions and principles of management [19]. The messages were compiled to inform education resources, including new websites and other educational material [19]. Through discussion, four research team members (EO, JM, IH, BW) selected ten messages that best represented first-line care [29]. The messages included at least one message from each of the six themes identified in the Delphi study to ensure comprehensiveness and comprehensibility. These messages were inherently relevant to the public because that was an important target of the Delphi study [19].

\section{Procedure}

To identify the anchors for the semantic differential scales, we conducted face-to-face interviews and online questionnaires. We presented the first independent sample of participants with low back pain $(n=23)$ with 10 messages that represented first-line care, and in a faceto-face interview, asked them two questions; "as someone with low back pain, what word would you use to describe this message" and "how does this message make you feel?" These open-ended questions generated 13 unique adjectives; (depressing, understanding, sad, confusing, anxious, interesting, discouraged, helpful, well cared for, agree, worried, frustrated, surprised). This method accounted for the anchors being relevant and comprehensible to the target population. One researcher (EO) contributed both complementary (e.g., a straightforward negative such as supportive/unsupportive) and graded (e.g., reassuring/confusing) antonyms to provide a second anchor and create thirteen semantic scales. A description of the process to develop the semantic differential scales is available in Additional file 1.

\section{Item reduction}

We tested the semantic differential scales in the second independent group of participants with low back pain $(\mathrm{n}=28)$. We constructed a questionnaire in a secure electronic form using Qualtrics [30]. This questionnaire presented 10 messages representing first-line care and asked participants to rate their responses using the thirteen semantic differential scales. We measured the correlation (Pearson's r) between items. We set the multicollinearity threshold at $r>0.85$, identified highly correlated pairs and eliminated one pair through discussion. The removed adjective pairs included depressing-hopeful, irrational-understandable, sad-happy, confusinginformative, anxious-confident, boring-interesting, discouraged-motivated, unhelpful-helpful, not cared forwell cared for. We chose two adjective pairs to represent affective components of attitude; frustrated-encouraged, worried-reassured, and two adjective pairs to represent cognitive components of attitude; disagree-agree, surprising-expected. Full details are available in Additional file 1.

Expert focus group An expert focus group $(\mathrm{n}=9)$ reviewed the final adjective pairs. The expert focus group consisted of five researchers and four clinicians with an interest in musculoskeletal health. The focus group included researchers with a range of experience from a graduate to senior researchers with over 20 years of research experience; the clinicians were all senior clinicians, each with over 15 years of clinical experience. The expert focus group did not recommend any changes to the semantic scales. We named the questionnaire the "AxELQ"; (Attitude toward Education and advice for Low-backpain) Questionnaire.

\section{Questionnaire draft}

The resulting preliminary AxEL-Q questionnaire had 40 items that included questions about the affective and cognitive components of attitude relative to ten statements of education and advice to represent first-line care. Each item was scored on a 0-6 Likert scale. The full details of the structure of the preliminary AxEL-Q, including details on the instructions given, response options and scoring algorithm, are available in Additional file 2.

\section{Evaluation of the AxEL-Q}

\section{Participants}

We evaluated the questionnaire draft in a sample of people with low back pain. We recruited people who had low back pain of any duration. This was a global study, there were no restrictions on what country or setting people were recruited from. Study participants were required to be aged over 18-years and fluent in English. We recruited one sample to represent the target population regarding age, sex, and important disease characteristics (e.g., severity, status, duration). We required a sample of $>200$ participants to satisfy the COSMIN recommendation 
that the sample size for assessment of construct validity should be five times the number of items and $>100$ [21]. We administered the AxEL-Q to consenting participants a second time to obtain retest data.

We recruited participants from:

- Databases of people with low back pain who had expressed an interest in research. We had access to a database of people with low back pain recruited from primary care centres in the Sydney metropoli$\tan$ area. These people were not included in previous research studies with our group but consented to future contact regarding research studies.

- Social media. We posted an invitation to participate in this research study on social media platforms, Facebook, and Twitter.

\section{Procedure}

Participants accessed the questionnaire via email or by following a link on social media. The questionnaire was in electronic form and was produced following our institutions' data security standards using Qualtrics [30]. Participants had access to an informed consent document and consented to be involved by proceeding with the survey. Participants were sent reminders to complete partially completed surveys on three occasions, if possible.

\section{Measures}

As well as the draft questionnaire participants completed demographic questions, including questions on age and sex and questions about the duration of low back pain and its intensity. In addition, participants completed two validated back pain questionnaires, the Back Beliefs Questionnaire (BBQ) [31] and the modified Pain Self-Efficacy Questionnaire (PSEQ) [32], to evaluate convergent validity. The $\mathrm{BBQ}$ is an instrument to measure beliefs and attitudes related to back pain [31]. The BBQ has 14 items, including five distractors (questions $4,5,7,9$ and 11) not included in the final score [31,33]. Responses are scored on a 5-point Likert scale from completely disagree (1 point) to completely agree (5 points); the total score ranges from 9 to 45 . Higher scores indicate more pessimistic beliefs about the consequences of low back pain. The modified PSEQ is an instrument based on the psychological construct of self-efficacy which refers to an individual's belief in their capacity to execute a behaviour necessary to achieve a specific task [34]. The modified PSEQ measures how confident participants feel about completing certain activities despite their pain. The modified PSEQ used had three questions [32]. Responses are scored on a 7-point scale from not at all confident $(0$ points) to completely confident (6 points). The total score ranges from 0 to 18 . Higher scores indicate greater selfefficacy despite low back pain. These questionnaires are available in Additional file 3.

To obtain test-retest data, we emailed participants the AxEL-Q 3 months after completing the questionnaire for the first time. We chose a 3 month time interval between test and retest to ensure the elapsed time period was long enough to prevent the recall of previous answers but short enough to assume that the participants' attitude may not change. Similarly, although some participants' attitudes may change depending on symptom trajectories, we expected attitude changes to correspond with changes on the modified PSEQ and used stable modified PSEQ scores as a reference. We recognise that 3-months was longer than commonly used intervals so to minimise variability we based stability on a small standard deviation. We considered a change on the modified PSEQ of less than 0.5 standard deviations over 3 months to be a stable score. We used the AxEL-Q responses from participants with stable PSEQ scores only to evaluate testretest reliability and measurement error.

\section{Data analysis}

We used descriptive statistics to characterise the sample. We reported means and standard deviations for continuous variables. We used frequencies and percentages to report categorical variables. We used the $\mathrm{R}$ environment for statistical computing to conduct the analyses [35]. We used psych package version 2.1.3 to conduct the factor analysis, irr package, version 0.84 .1 to determine interclass correlation coefficient and rel package, version 1.4.2 to determine the standard error of measurement.

\section{Construct validity}

Structural validity Structural validity involves evaluating how well the scoring structure of the instrument corresponds to the construct being measured [22]. We used exploratory factor analysis (EFA) to evaluate the structural validity and to reduce the number of items in the questionnaire draft. We explored scree plots, parallel analysis, and Kaiser criterion to determine the most appropriate number of factors in keeping with standard EFA procedures. We used maximum likelihood estimation with oblimin rotation for factor extraction [36]. We used factor loading patterns to identify and extract items. Correlations of items to factors of less than 0.5 were sequentially deleted [37]. We continued a data-driven iterative process to achieve simple structure. We measured fit adequacy using the Tucker Lewis index (TLI) and comparative fit index (CFI). The TFL is an incremental fit index whereby bigger values indicate better fit. Values larger than 0.95 are interpreted as acceptable fit [38]. Values for CFI range between 0.0 and 1.0, with values closer to 1.0 indicating 
good fit. A CFI value of $\geq 0.90$ is recommended [39]. Root mean square error of approximation (RMSEA) is an index of the difference between the observed covariance matrix and the hypothesised covariance matrix. RMSEA values smaller than 0.06 indicate a good fit, between 0.06 and 0.10 a mediocre fit and above 0.10 a poor fit [39]. Similarly for the root mean square of the residual (RMSR) index, smaller values indicate a better fit [40].

Hypotheses testing for convergent validity Convergent validity measures the degree to which the scores on the AxEL-Q are consistent with hypotheses based on the assumption that the questionnaire validly measures attitude toward first-line care of low back pain [22]. There is no 'gold standard' for measuring attitude toward first-line care, therefore we evaluated convergent validity by testing hypotheses about the size and direction of the relationship between the AxEL-Q and two other validated back pain questionnaires, the BBQ and the modified PSEQ. The data was analysed as continuous data because there were six response options on the semantic differential scales, using Pearson's $r$ to test correlations between the AxEL-Q and two scales. We considered correlation coefficients $<0.30$ as weak, coefficients between 0.30 and 0.49 as moderate, and coefficients $\geq 0.50$ as strong [41].

Higher scores on $\mathrm{BBQ}$ indicate more pessimistic beliefs about the consequences of low back pain, we hypothesised that those with more pessimistic beliefs would be less likely to have a positive attitude toward statements of education and advice to represent first-line care. Therefore, we hypothesised that responses on the AxEL-Q would be inversely correlated to responses on the $\mathrm{BBQ}$. Both questionnaires are designed to measure different but theoretically overlapping constructs, so we expected the strength of this relationship to be moderate corresponding to a Pearson's $r$ of -0.30 to -0.49 . Conversely, as higher scores on the modified PSEQ indicate more confidence despite low back pain, we hypothesised that people with higher pain related self-efficacy would have a positive attitude toward statements of education and advice to represent first-line care. Therefore, we expected that responses on the AxEL-Q would be positively correlated to responses on the modified PSEQ. Both questionnaires also measure different but theoretically overlapping constructs, so we expected the strength of this relationship to be moderate, corresponding to a Pearson's $r$ of $0.30-0.49$.

\section{Reliability}

Internal consistency Internal consistency measures the degree to which items on the same scale are interrelated [20]. Following the EFA, we calculated Cronbach's $\alpha$ for each factor. We considered values of Cronbach's $\alpha<0.70$ as inadequate, values between 0.70 and 0.79 as adequate, values between 0.80 and 0.89 as good, and values $\geq 0.90$ as excellent [42].

Test-retest reliability Test-retest reliability refers to the proportion of the total variance in the measurements due to true differences [22]. We used a two-way randomeffects model, interclass correlation coefficient (ICC) $(2,1)$, as the participants came from a random sample. This model allows the questionnaire to be generalisable to different cohorts [20], such as patients with low back pain attending tertiary care. An ICC score of $\geq 0.70$ was considered adequate [43].

Measurement error The Standard Error of Measurement (SEM) accounts for the systematic and random error of a participants' score that is not attributed to true changes in the construct to be measured [22]. We calculated the SEM by calculating the square root of the test-retest variance plus the residual variance to account for any systematic differences between the testing sessions [44]. This method is analogous to the two-way random-effects model we used to calculate test-retest reliability [20]. Larger scores indicate large variability, and smaller scores indicate minimal variability between testing sessions.

Minimal detectable change (MDC) MDC is the threshold for determining true changes beyond measurement error and was calculated based on the SEM of the test-retest reliability [22]. The MDC was calculated as $S E M \times z \times \sqrt{2},[20,36,45]$ where SEM is the standard error of measurement and $\mathrm{z}=1.96$ ( $\mathrm{z}$ score for estimating a $95 \%$ confidence interval). We used the square root of two, because there was a total of two measurements for test-retest reliability.

\section{Floor and ceiling effects}

Floor and ceiling effects are present if the questionnaire scores are either too low or too high so that detecting a deterioration or improvement would not be possible [22] We defined floor and ceiling effects present if more than $15 \%$ of the participants reported the worst (minimum) or best (maximum) possible score [45].

\section{Labelling}

We reviewed the questionnaire in the context of evidence-based theory to ensure relevance to the target population and to label the factors.

\section{Results}

\section{Descriptive statistics}

The development process resulted in a questionnaire draft with 40-items. We evaluated the questionnaire draft 
in a sample of 345 participants with low back pain. One hundred and seventy-four participants who provided an email address were administered the survey twice, including the AxEL-Q, BBQ and modified PSEQ. Seventy-one participants of those one hundred and seventyfour provided stable retest data based on their modified PSEQ score. Table 1 outlines the demographic details of the participants. There were incomplete items for 32 participants, less than $10 \%$ of the overall sample. As we had exceeded our required sample size [46], data from these participants were omitted, leaving data from 313 participants for analysis. For those that responded to the followup questionnaire there were no missing data.

\section{Construct validity} Structural validity

Additional file 4 outlines the exploratory factor analysis results, including the four different methods used to determine how many factors best describe the data. A 3-Factor model achieved the best balance of goodness of fit, validity, reliability, and fitted with evidence-based theory. A simple structure was achieved after five rounds. The three factors together explained $65 \%$ of the variance in the model. Factor 1 explained $30 \%$ of variance, Factor 2 18\%, Factor 3 17\%. The resulting questionnaire included 17 items, the score range for Factor 1 was $0-54,0$ being the minimum possible score and 54 the maximum possible score, for Factor $20-24$ and Factor $30-24$. Full details of the EFA results including fit statistics are available in Additional file 5.

\section{Hypotheses testing for convergent validity}

All factors were strongly inversely correlated with the $\mathrm{BBQ}$, suggesting those with a negative attitude toward first-line care had more pessimistic beliefs about low back pain. All factors on the 3-Factor AxEL-Q were moderate to strongly positively correlated with the modified PSEQ, suggesting that those with a positive attitude toward first-line care had greater pain-related self-efficacy. These results are presented in Table 2.

\section{Reliability Internal consistency}

Each factor demonstrated good to excellent values of Cronbach's $\alpha$; Factor $1 \alpha=0.92$, Factor $2 \alpha=0.91$ and Factor $3 \alpha=0.90$.

\section{ICC, SEM and MDC}

The 3-Factor model demonstrated adequate ICC, but moderate to high values of SEM and MDC. Table 2 outlines the ICC, SEM and MDC.

\section{Floor and ceiling effects}

The 3-Factor model did not display a floor or ceiling effect. Table 2 outlines the percentage of participants

Table 1 Descriptive statistics

\begin{tabular}{|c|c|c|}
\hline Characteristic & Total sample, $n=313$ & Retest cohort, $n=71$ \\
\hline Age in years, mean (SD) & $48.9(16.7)$ & $53.8(14.2)$ \\
\hline Female, $\mathrm{n}(\%)$ & $205(65 \%)$ & $45(63 \%)$ \\
\hline Cultural background, $\mathrm{n}(\%)^{\mathrm{a}}$ & $45(14 \%)$ & NA \\
\hline Health literacy, mean (SD) ${ }^{b}$ & $4.6(0.7)$ & NA \\
\hline $\begin{array}{l}\text { Number of sessions of moderate-intensity physical activity per week, } \\
\text { mean }(S D)^{c}\end{array}$ & $0.8(0.8)$ & NA \\
\hline $\begin{array}{l}\text { Number of sessions of vigorous-intensity physical activity per week, } \\
\text { mean (SD) }\end{array}$ & $1.6(1.0)$ & NA \\
\hline Low back pain intensity, mean (SD)e & $3.4(1.0)$ & $5.5(2.3)$ \\
\hline Chronic low back pain, n (\%) & $252(81 \%)$ & $45(63 \%)$ \\
\hline Back Beliefs, mean (SD) ${ }^{f}$ & $26.7(7.1)$ & $27.6(7.5)$ \\
\hline Pain Self Efficacy, mean (SD) ${ }^{g}$ & $12.7(4.8)$ & $12.5(4.4)$ \\
\hline
\end{tabular}

SD standard deviation, NA not asked

${ }^{a}$ Measured by asking whether participants spoke a language other than English at home, with answer options either yes or no

${ }^{b}$ Measured by asking how confident you are filling out medical forms by yourself with a range from 0 (not at all confident) to 5 (extremely confident)

${ }^{c}$ Moderate-intensity physical activity described as; increases your heart rate or makes you breathe harder than normal. (e.g., carrying light loads, bicycling at a regular pace or doubles tennis)

${ }^{d}$ Vigorous-intensity physical activity described as; makes you sweat or puff and pant. (e.g., heavy lifting, digging, jogging, aerobics, or fast bicycling)

e Numeric rating scale with a range from 0 (no pain) to 10 (worst pain possible)

${ }^{f}$ Back Beliefs Questionnaire with a range from 9 (less pessimistic beliefs) to 45 (more pessimistic beliefs)

${ }^{9}$ Modified pain self-efficacy questionnaire with a range from 0 (low self-efficacy) to 18 (high self-efficacy) 
Table 2 Results of reliability, measurement error, construct validity and ceiling and floor effect analyses for the AxEL-Q

\begin{tabular}{|c|c|c|c|c|c|c|c|}
\hline \multirow[t]{2}{*}{3 Factor model } & \multicolumn{2}{|l|}{ Construct validity } & \multirow[t]{2}{*}{$\mathrm{ICC}^{\mathrm{a}}$} & \multirow[t]{2}{*}{ SEM $^{\mathbf{b}}$} & \multirow[t]{2}{*}{$M M^{c}$} & \multirow{2}{*}{$\begin{array}{l}\text { Ceiling effects } \\
\% \text { Scoring } \\
\text { maximum score } \\
\text { (\%) }\end{array}$} & \multirow{2}{*}{$\begin{array}{l}\text { Floor effects } \\
\% \text { Scoring } \\
\text { minimum } \\
\text { score }\end{array}$} \\
\hline & Back beliefs questionnaire & $\begin{array}{l}\text { Modified pain self- } \\
\text { efficacy questionnaire }\end{array}$ & & & & & \\
\hline \multirow[t]{3}{*}{ Factor 1} & $-0.56^{d}$ & $0.55^{\mathrm{d}}$ & $0.71^{d}$ & $5.59^{d}$ & 15.49 & 6.4 & 0 \\
\hline & $(-0.63$ to -0.48$)$ & (0.46 to 0.62$)$ & & & & & \\
\hline & (0.58 to 0.81$)$ & (4.63 to 6.54$)$ & & & & & \\
\hline \multirow[t]{3}{*}{ Factor 2} & $-0.50^{d}$ & $0.37^{d}$ & $0.73^{d}$ & $3.51^{d}$ & 9.73 & 2.9 & $5.1 \%$ \\
\hline & $(-0.58$ to -0.41$)$ & (0.27 to 0.46$)$ & & & & & \\
\hline & (0.60 to 0.82$)$ & (2.96 to 4.06$)$ & & & & & \\
\hline \multirow[t]{3}{*}{ Factor 3} & $-0.50^{d}$ & $0.35^{\mathrm{d}}$ & $0.79^{d}$ & $2.68^{d}$ & 7.43 & 4.8 & $1.3 \%$ \\
\hline & $(-0.58$ to -0.41$)$ & (0.24 to 0.44$)$ & & & & & \\
\hline & (0.64 to 0.87 ) & (2.23 to 3.12 ) & & & & & \\
\hline
\end{tabular}

All effects are presented with their $95 \%$ confidence intervals

${ }^{a}$ Interclass correlation coefficient

${ }^{\mathrm{b}}$ Standard error of measurement

'Minimal detectable change

${ }^{d} p<0.01$

who scored the maximum or minimum score for each factor.

\section{Labelling}

The three factors complemented clinical practice guidelines for the management of low back pain and were named accordingly Factor 1; Attitude toward staying active, Factor 2; Attitude toward low back pain being rarely caused by a serious health problem, Factor 3; Attitude toward not needing to know the cause of back pain to manage it effectively. The full details of the final-version of the 3-Factor model (titled the AxEL-Q) are available in Fig. 2.

\section{Discussion}

The AxEL-Q provides clinicians with a valid and reliable tool to understand patient attitudes toward first-line care for low back pain. Each subscale demonstrated acceptable construct validity and reliability, meaning that the questionnaire could be used as a whole or as individual subscales. The independent utility of the subscales allows clinicians to understand attitudes toward distinct aspects of first line care in people with low back pain.

The AxEL-Q may help inform and guide the management of people presenting with low back pain. This questionnaire can provide clinicians with an insight to effectively implement current recommendations at the outset of a clinical encounter. For example, if a patient scores high on 'the attitude towards not needing to know the cause of back pain to manage it effectively, the clinician could devote more time during the consultation towards other aspects of first-line care such as promoting physical activity. Whereas if a patient has a negative attitude towards this factor, the clinician could prioritise time and resources to discuss how imaging may do more harm than good when serious conditions are not suspected and is likely to prolong recovery [47]. Future research would be needed to evaluate the effectiveness of using the AxEL-Q in this way.

Five statements that represented first line care were omitted as part of the EFA process but may still have some relevance for clinical practice. We conducted a separate analysis to understand if any of the 10 statements that were included in the questionnaire draft were predictive of self-managing low back pain in people with low back pain of different durations. Our findings indicate that people's attitude toward certain key messages was predictive of their intention to self-manage, but which message and the size of the effect was dependent on whether someone had low back pain and for how long [48].

\section{Content validity}

We comprehensively represented first-line care for low back pain by developing the questionnaire items relative to ten expert and consumer endorsed advice and education statements. Although the questionnaire was developed within the COSMIN framework, we did not conduct qualitative testing before testing construct validity. Instead, we assumed relevance, comprehensiveness, and comprehensibility, but qualitative testing would have 
AxEL-Q

Check the most appropriate response

Factor 1-Attitude toward staying active ${ }^{a}$

\begin{tabular}{|c|c|c|c|c|c|c|c|}
\hline & $\begin{array}{l}\text { Strongly } \\
\text { disagree }\end{array}$ & Disagree & $\begin{array}{l}\text { Somewhat } \\
\text { disagree }\end{array}$ & $\begin{array}{l}\text { Neither } \\
\text { disagree nor } \\
\text { agree }\end{array}$ & $\begin{array}{l}\text { Somewhat } \\
\text { agree }\end{array}$ & Agree & $\begin{array}{l}\text { Strongly } \\
\text { agree }\end{array}$ \\
\hline $\begin{array}{l}\text { Staying active helps prevent long term back } \\
\text { problems }\end{array}$ & 0 & 0 & 0 & 0 & 0 & 0 & 0 \\
\hline $\begin{array}{l}\text { When you have low back pain, it is important to } \\
\text { take ownership of your own wellbeing }\end{array}$ & 0 & 0 & 0 & 0 & 0 & 0 & 0 \\
\hline $\begin{array}{l}\text { You need to pace yourself to return to your usual } \\
\text { activities }\end{array}$ & $\bigcirc$ & $\bigcirc$ & $\bigcirc$ & 0 & 0 & 0 & $\bigcirc$ \\
\hline & $\begin{array}{l}\text { Very } \\
\text { worrying }\end{array}$ & Worrying & $\begin{array}{l}\text { Somewhat } \\
\text { worrying }\end{array}$ & $\begin{array}{l}\text { Neither } \\
\text { worrying } \\
\text { nor } \\
\text { reassuring }\end{array}$ & $\begin{array}{l}\text { Somewhat } \\
\text { reassuring }\end{array}$ & Reassuring & $\begin{array}{l}\text { Very } \\
\text { reassuring }\end{array}$ \\
\hline $\begin{array}{l}\text { Staying active helps prevent long term back } \\
\text { problems }\end{array}$ & 0 & 0 & 0 & 0 & 0 & 0 & 0 \\
\hline $\begin{array}{l}\text { When you have low back pain, it is important to } \\
\text { take ownership of your own wellbeing }\end{array}$ & 0 & 0 & 0 & 0 & 0 & 0 & 0 \\
\hline $\begin{array}{l}\text { You need to pace yourself to return to your usual } \\
\text { activities }\end{array}$ & 0 & $\bigcirc$ & $\bigcirc$ & 0 & 0 & 0 & 0 \\
\hline & $\begin{array}{l}\text { Very } \\
\text { frustrating }\end{array}$ & Frustrating & $\begin{array}{l}\text { Somewhat } \\
\text { frustrating }\end{array}$ & $\begin{array}{l}\text { Neither } \\
\text { frustrating } \\
\text { nor } \\
\text { encouraging }\end{array}$ & $\begin{array}{l}\text { Somewhat } \\
\text { encouraging }\end{array}$ & Encouraging & $\begin{array}{l}\text { Very } \\
\text { encouraging }\end{array}$ \\
\hline $\begin{array}{l}\text { Staying active helps prevent long term back } \\
\text { problems }\end{array}$ & 0 & 0 & 0 & 0 & 0 & 0 & 0 \\
\hline $\begin{array}{l}\text { When you have low back pain, it is important to } \\
\text { take ownership of your own wellbeing }\end{array}$ & 0 & 0 & 0 & 0 & 0 & 0 & 0 \\
\hline $\begin{array}{l}\text { You need to pace yourself to return to your usual } \\
\text { activities }\end{array}$ & 0 & $\bigcirc$ & $\bigcirc$ & 0 & 0 & $\bigcirc$ & $\bigcirc$ \\
\hline
\end{tabular}

Factor 2- Attitude toward low back pain being rarely caused by a serious health problem

\begin{tabular}{|c|c|c|c|c|c|c|c|}
\hline & $\begin{array}{l}\text { Strongly } \\
\text { disagree }\end{array}$ & Disagree & $\begin{array}{l}\text { Somewhat } \\
\text { disagree }\end{array}$ & $\begin{array}{l}\text { Neither } \\
\text { disagree nor } \\
\text { agree }\end{array}$ & $\begin{array}{l}\text { Somewhat } \\
\text { agree }\end{array}$ & Agree & $\begin{array}{l}\text { Strongly } \\
\text { agree }\end{array}$ \\
\hline $\begin{array}{l}\text { It is rare for low back pain to be caused by a more } \\
\text { serious health problem }\end{array}$ & 0 & O & O & 0 & O & 0 & O \\
\hline & $\begin{array}{l}\text { Very } \\
\text { surprising }\end{array}$ & Surprising & $\begin{array}{l}\text { Somewhat } \\
\text { surprising }\end{array}$ & $\begin{array}{l}\text { Neither } \\
\text { surprising } \\
\text { nor } \\
\text { expected }\end{array}$ & $\begin{array}{l}\text { Somewhat } \\
\text { expected }\end{array}$ & Expected & $\begin{array}{l}\text { Very } \\
\text { expected }\end{array}$ \\
\hline $\begin{array}{l}\text { It is rare for low back pain to be caused by a more } \\
\text { serious health problem }\end{array}$ & 0 & O & 0 & O & O & O & 0 \\
\hline & $\begin{array}{l}\text { Very } \\
\text { worrying }\end{array}$ & Worrying & $\begin{array}{l}\text { Somewhat } \\
\text { worrying }\end{array}$ & $\begin{array}{l}\text { Neither } \\
\text { worrying } \\
\text { nor } \\
\text { reassuring }\end{array}$ & $\begin{array}{l}\text { Somewhat } \\
\text { reassuring }\end{array}$ & Reassuring & $\begin{array}{l}\text { Very } \\
\text { reassuring }\end{array}$ \\
\hline $\begin{array}{l}\text { It is rare for low back pain to be caused by a more } \\
\text { serious health problem }\end{array}$ & 0 & 0 & 0 & O & 0 & 0 & 0 \\
\hline & $\begin{array}{l}\text { Very } \\
\text { frustrating }\end{array}$ & Frustrating & $\begin{array}{l}\text { Somewhat } \\
\text { frustrating }\end{array}$ & $\begin{array}{l}\text { Neither } \\
\text { frustrating } \\
\text { nor } \\
\text { encouraging }\end{array}$ & $\begin{array}{l}\text { Somewhat } \\
\text { encouraging }\end{array}$ & Encouraging & $\begin{array}{l}\text { Very } \\
\text { encouraging }\end{array}$ \\
\hline $\begin{array}{l}\text { It is rare for low back pain to be caused by a more } \\
\text { serious health problem }\end{array}$ & O & O & $\bigcirc$ & 0 & 0 & 0 & 0 \\
\hline
\end{tabular}

Fig. 2 AxEL-Q 


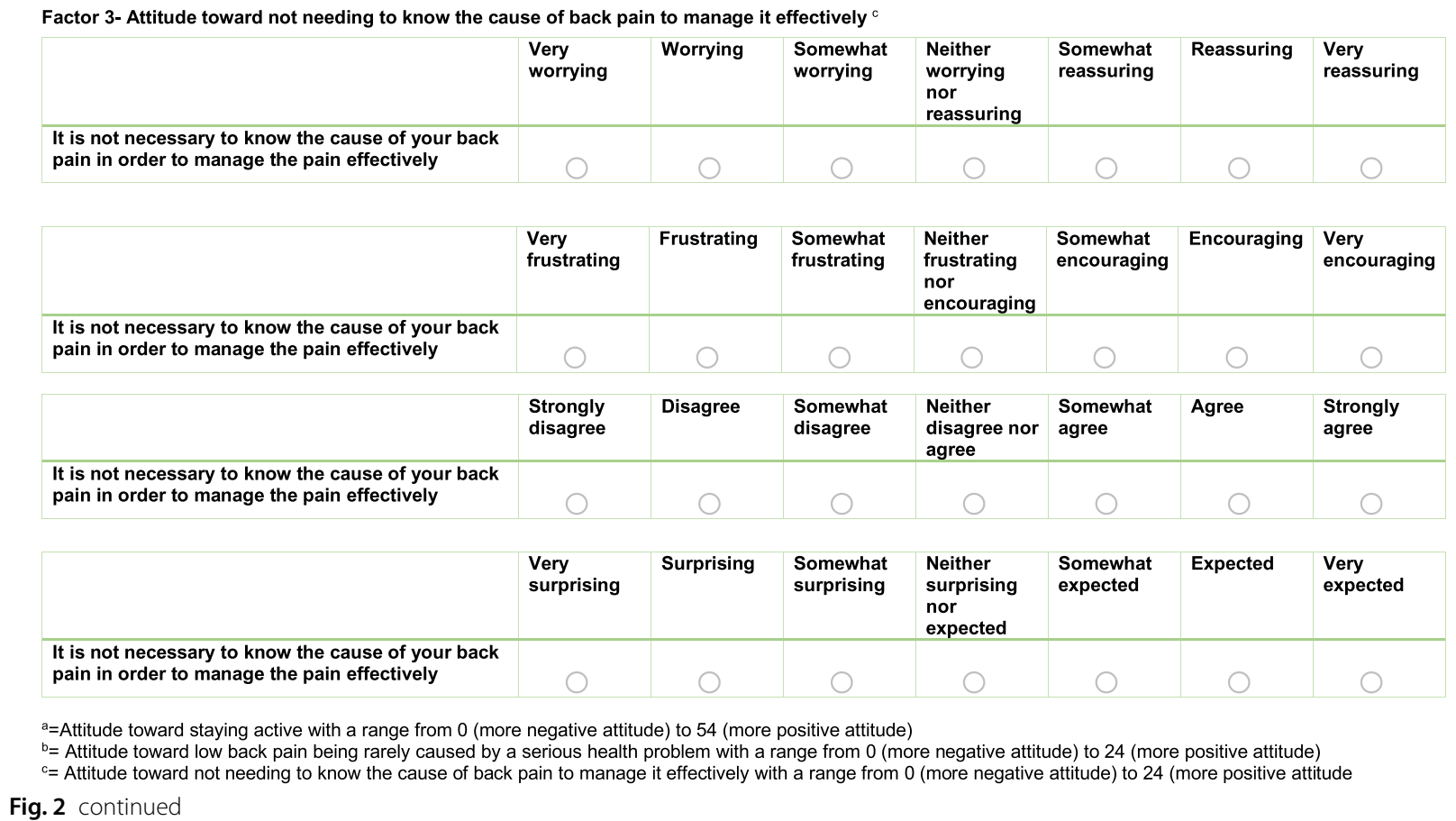

${ }^{a}=$ Attitude toward staying active with a range from 0 (more negative attitude) to 54 (more positive attitude)

$b=$ Attitude toward low back pain being rarely caused by a serious health problem with a range from 0 (more negative attitude) to 24 (more positive attitude)

$c=$ Attitude toward not needing to know the cause of back pain to manage it effectively with a range from 0 (more negative attitude) to 24 (more positive attitude

Fig. 2 continued

confirmed these assumptions. We acknowledge that this is a limitation of this study.

\section{Construct validity}

The exploratory factor analysis demonstrated a 3-Factor model in keeping with the conceptual framework that attitude toward first-line care for low back pain is a multidimensional construct, measured indirectly using multiple observable items. Five statements that represented first line care were omitted as part of the EFA process but may still have some relevance for clinical practice.

The AxEL-Q demonstrated good construct validity suggesting that it measures what it is designed to measure, in keeping with prior hypotheses. The strength of the relationship with the BBQ and modified PSEQ supports that unhelpful beliefs underpin unhelpful attitudes, and through the relationship with self-efficacy it suggests the AxEL-Q has promise at predicting future behaviour. In general these relationships suggest the value of the AxEL$\mathrm{Q}$ to complement questionnaires commonly used with people with low back pain by evaluating attitudes toward specific elements of first-care that would not be captured in general questionnaires.

\section{Reliability}

Each factor on the AxEL-Q demonstrated good internal consistency. The ICC is adequate, meaning that it can differentiate between people while remaining relatively stable between testing sessions. The SEM ranges from $10.4 \%$ of the overall score for Factor 1-14.6\% for Factor 2; these values are in keeping with other validated patientreported outcomes [36]. The MDC was high; for example, a change score of more than 15 points for Factor 1 ( $>28 \%$ change) would be necessary to determine a true change. A high MDC is a common issue with patientreported questionnaires [36].

\section{Floor and ceiling effects}

$6.4 \%$ of responses recorded the maximum possible score. The included participants expressed an interest in health research. These participants may be more likely to have a positive attitude toward first-line care as they had volunteered for research that included an education component. Floor and ceiling effects are sensitive to the population under study so the result might be different in a clinical population.

\section{Strengths and weaknesses}

A key strength of this study is the rigorous method used to develop the AxEL-Q and evaluate its clinimetric performance, in line with the COSMIN recommendations $[20,22,23]$. Other validated questionnaires designed to measure attitude measure levels of agreement with particular statements $[15,17,18,49]$, in comparison the AxEL-Q appears to be a more sophisticated measure that considers both cognitive and affective components 
of attitude. However, with up to seventeen questions, we do not anticipate excessive participant burden.

This study has some weaknesses. Attitude is only one component of intention, and therefore provides a limited insight to the subsequent behaviour. The theory of planned behaviour model suggests that perceived behavioural control and subjective norms together with attitude shape an individuals' behavioural intentions [50]. Evaluating the clinical utility to understand if attitudes actually correspond with the predicted behaviour is necessary. Second, qualitative testing is an important aspect of designing questionnaires. We undertook a comprehensive process to design the questionnaire but specific qualitative testing would have strengthened the results. Third, there was a 3-month interval between the first and retest data collection period. We allowed this interval because attitude and self-efficacy are considered stable constructs and we anticipated that this time frame was necessary to prevent recall of initial responses. However we acknowledge that intervals from 14 days to 1 month are more commonly used. Fourth, we had incomplete data for 32 participants. We suggest this was due to questionnaire fatigue due to the large number of questions. Fifth, the implication of the SEM and the MCD will not be evident until the AxEL$\mathrm{Q}$ is used to assess a change in attitude as part of an intervention or longitudinal study. These study designs where we anticipate a change over time or between groups will provide an understanding of how realistic it is to determine a true change, i.e. a change that is greater than the value of the SEM. Future studies are needed to evaluate the measurement properties of the AxEL Questionnaire by strictly focusing on Clinimetric Patient-Reported Outcome Measures (CLIPROM) criteria that represent a step forward to the development of new clinimetric indices and validation process of existing rating scales to be used in clinical research and practice [51].

\section{Conclusion}

The underlying theoretical basis of the AxEL-Q is that attitude toward first-line care predicts intention to behave in line with that recommendation. Further evaluation should test the responsiveness of the AxEL-Q in a longitudinal design such as in a randomised controlled trial and calculating the minimally clinically important change could improve the interpretability of the AxEL-Q.

Despite these limitations the questionnaire enables clinicians to efficiently personalise first-line care to ensure that it aligns with the patient's attitudes which may improve patient satisfaction, and potentially improve treatment outcomes.

\section{Supplementary Information}

The online version contains supplementary material available at https://doi. org/10.1186/s12955-021-01908-4.

Additional file 1. Development of the AxEL-Q.

Additional file 2. Questionnaire draft.

Additional file 3. Back Beliefs Questionnaire \& the Modified Pain SelfEfficacy Questionnaire.

Additional file 4. Exploratory Factor Analysis (EFA) results.

Additional file 5. The three-factor Model.

\section{Acknowledgements}

None.

\section{Author contributions}

ETO conceived the study, provided methodological expertise and wrote the protocol. IWS provided qualitative, methodological and clinical area expertise. MDJ provided qualitative, methodological and clinical area expertise. EKL provided qualitative, methodological and clinical area expertise. ACT provided methodological expertise. AGC provided methodological expertise. BMW provided methodological expertise. SS provided methodological expertise. SO provided methodological expertise. IAH provided methodological expertise. JHM is the guarantor and conceived the study, provided clinical area expertise. All authors read, contributed to and approved the final version of the manuscript.

\section{Funding}

This research project did not receive any specific grant from funding agencies in the public, commercial, or not-for-profit sectors. ETO was supported by Australian Commonwealth Government Research Training Program scholarship and a Neuroscience Research Australia PhD Candidature Additional file Scholarship.

\section{Data sharing}

The datasets used and analysed during the current study are available from the corresponding author on reasonable request. The study protocol including the analysis plan is publicly available on the Open Science Framework https://osf.io/9wncz/ Data will be made publicly available on the Open Science Framework on publication.

\section{Declarations}

\section{Ethics approval and consent to participate}

The University of New South Wales (UNSW) Human Research Ethics Committee (HREC), approved this study (reference number HC17919) prior to data collection

\section{Consent for publication}

All authors consent to publication of this manuscript.

\section{Competing interests}

The authors have no known declarations.

\section{Author details}

${ }^{1}$ Centre for Pain IMPACT, Neuroscience Research Australia (NeuRA), 139 Barker Street, Randwick, NSW 2031, Australia. ${ }^{2}$ Prince of Wales Clinical School, University of New South Wales, Sydney, NSW, Australia. ${ }^{3}$ School of Community Health, Charles Sturt University, Port Macquarie, NSW, Australia. ${ }^{4}$ School of Health Sciences, Faculty of Medicine and Health, University of New South Wales, Sydney, NSW, Australia. ${ }^{5}$ IMPACT in Health, UniSA: Allied Health and Human Performance, The University of South Australia, Adelaide, SA, Australia. ${ }^{6}$ Institute for Musculoskeletal Health, Sydney School of Public Health, Faculty of Medicine and Health, The University of Sydney, Sydney, NSW, Australia. 'Faculty of Medicine, Nursing and Midwifery and Health Sciences, The University of Notre Dame Australia, Fremantle, WA, Australia. ${ }^{8}$ South Western Sydney Clinical School, Liverpool Hospital, The University of New South Wales, 
Sydney, NSW, Australia. ${ }^{9}$ Institute of Bone and Joint Research, Kolling Institute, The University of Sydney, Sydney, NSW, Australia. ${ }^{10}$ Ingham Institute of Applied Medical Research, Liverpool, Sydney, NSW, Australia.

Received: 27 September 2021 Accepted: 13 December 2021 Published online: 10 January 2022

\section{References}

1. Vos T, Allen C, Arora M, Barber RM, Brown A, Carter A, et al. Global, regional, and national incidence, prevalence, and years lived with disability for 310 diseases and injuries, 1990-2015: a systematic analysis for the Global Burden of Disease Study 2015. Lancet. 2016;388:1545-602.

2. Abbafati C, Machado DB, Cislaghi B, Salman OM, Collaborators G, et al. Collaborators G 2019 D and I. Global burden of 369 diseases and injuries in 204 countries and territories, 1990-2019: a systematic analysis for the Global Burden of Disease Study 2019. Lancet. 2020;396:1204-22.

3. Hartvigsen J, Hancock MJ, Kongsted A, Louw Q, Ferreira ML, Genevay S, et al. What low back pain is and why we need to pay attention. Lancet. 2018;391:2356-67.

4. Traeger AC, Buchbinder R, Elshaug AG, Croft PR, Maher CG. Care for low back pain: Can health systems deliver? Bull World Health Organ. 2019:97:423-33.

5. Bernstein IA, Malik Q, Carville S, Ward S. Low back pain and sciatica: summary of NICE guidance. BMJ. 2017;356:10-3. https://doi.org/10.1136/bmj. i6748.

6. Dagenais S, Tricco AC, Haldeman S. Synthesis of recommendations for the assessment and management of low back pain from recent clinical practice guidelines. Spine J. 2010;10:514-29. https://doi.org/10.1016/j. spinee.2010.03.032.

7. Koes BW, Van Tulder M, Lin C-WC, Macedo LG, Mcauley J, Maher C. An updated overview of clinical guidelines for the management of nonspecific low back pain in primary care. Eur Spine J. 2010;19:2075-94. https://doi.org/10.1007/s00586-010-1502-y.

8. Foster NE, Anema JR, Cherkin D, Chou R, Cohen SP, Gross DP, et al. Prevention and treatment of low back pain: evidence, challenges, and promising directions. Lancet. 2018. https://doi.org/10.1016/S0140-6736(18)30489-6.

9. Kamper SJ, Logan G, Copsey B, Thompson J, Machado GC, AbdelShaheed C, et al. What is usual care for low back pain? A systematic review of health care provided to patients with low back pain in family practice and emergency departments. Pain. 2020;161:694-702.

10. Lim YZ, Chou L, Au RT, Seneviwickrama KMD, Cicuttini FM, Briggs AM, et al. People with low back pain want clear, consistent and personalised information on prognosis, treatment options and self-management strategies: a systematic review. J Physiother. 2019;65:124-35. https://doi. org/10.1016/j.jphys.2019.05.010.

11. Foster NE, Anema JR, Cherkin D, Chou R, Cohen SP, Gross DP, et al. Prevention and treatment of low back pain: evidence, challenges, and promising directions. Lancet. 2018:391:2368-83.

12. Bishop FL, Dima A, Ngui J, Little P, Moss-Morris R, Foster NE, et al. "Lovely pie in the sky plans": a qualitative study of clinicians' perspectives on guidelines for managing low back pain in primary care in England. Spine (Phila Pa 1976). 2015;40:1842.

13. Slade SC, Kent P, Patel S, Bucknall T, Buchbinder R. Barriers to primary care clinician adherence to clinical guidelines for the management of low back pain: a systematic review and metasynthesis of qualitative studies. Clin J Pain. 2016;32:800-16.

14. Rainville J, Bagnall D, Phalen L. Health care providers' attitudes and beliefs about functional impairments and chronic back pain. Clin J Pain. 1995:11:287-95.

15. Jensen MP, Turner JA, Romano JM. Pain belief assessment: a comparison of the short and long versions of the survey of pain attitudes. J Pain. 2000;1:138-50.

16. Darlow B, Perry M, Mathieson F, Stanley J, Melloh M, Marsh R, et al. The development and exploratory analysis of the back pain attitudes questionnaire (Back-PAQ). BMJ Open. 2014;4:e005251. https://doi.org/10.1136/ bmjopen-2014-005251.

17. Riley J, Ahern D, Follick M. Chronic pain and functional impairment: assessing beliefs about their relationship. Arch Phys Med Rehabil. 1988;69:579-82.
18. Slater MA, Hall HF, Atkinson JH, Garfin SR. Pain and impairment beliefs in chronic low back pain: validation of the pain and impairment relationship scale (PAIRS). Pain. 1991;44:51-6.

19. French SD, Nielsen M, Hall L, Nicolson PJA, Van Tulder M, Bennell KL, et al. Essential key messages about diagnosis, imaging, and self-care for people with low back pain: a modified Delphi study of consumer and expert opinions. Pain. 2019;160:2787-97.

20. Mokkink LB, Terwee CB, Patrick DL, Alonso J, Stratford PW, Knol DL, et al. The COSMIN checklist for assessing the methodological quality of studies on measurement properties of health status measurement instruments: an international Delphi study. Qual Life Res. 2010;19:539-49.

21. Mokkink LB, Terwee CB, Patrick DL, Alonso J, Stratford PW, Knol DL, et al. The COSMIN checklist for evaluating the methodological quality of studies on measurement properties. Qual Life Res. 2014;63:32. https://doi.org/ 10.1186/1471-2288-10-22.

22. Mokkink LB, Terwee CB, Patrick DL, Alonso J, Stratford PW, Knol DL, et al. The COSMIN study reached international consensus on taxonomy, terminology, and definitions of measurement properties for health-related patient-reported outcomes. J Clin Epidemiol. 2010;63:737-45. https://doi. org/10.1016/j.jclinepi.2010.02.006.

23. Mokkink LB, de Vet HCW, Prinsen CAC, Patrick DL, Alonso J, Bouter LM, et al. COSMIN risk of bias checklist for systematic reviews of patientreported outcome measures. Qual Life Res. 2018;27:1171-9. https://doi. org/10.1007/s11136-017-1765-4.

24. Cappelleri JC, Lundy JJ, Hays RD. Overview of classical test theory and item response theory for quantitative assessment of items in developing patient-reported outcome measures. Clin Ther. 2014;36:648-62.

25. Katz D. The functional approach to the study of attitudes. Public Opin Q. 1960;24:163-204.

26. Bergman MM. A Theoretical note on the differences between attitudes, opinions, and values. Swiss Polit Sci Rev. 1998;4:81-93.

27. Al-hindawe J. Considerations when constructing a semantic differential scale. La Trobe Work Pap Linguist. 1996;9:1-9.

28. Heise DR. The semantic differential and attitude research. In: Summers GF, editor. Attitude measurement. Chicago: Rand McNally; 1970. p. 235-53.

29. Oliveira CB, Maher CG, Pinto RZ, Traeger AC, Lin CWC, Chenot JF, et al. Clinical practice guidelines for the management of non-specific low back pain in primary care: an updated overview. Eur Spine J. 2018;27:2791803. https://doi.org/10.1007/s00586-018-5673-2.

30. Smith R, Orgill S, Smith SM, Smith J. Qualtrics XM. The leading experience management software. 2002. https://www.qualtrics.com.

31. Symonds TL, Burton AK, Tillotson KM, Main CJ. Do attitudes and beliefs influence work loss due to low back trouble? Occup Med (Chic III). 1996;46:25-32.

32. Nicholas MK, McGuire BE, Asghari A. A 2-item short form of the pain self-efficacy questionnaire: development and psychometric evaluation of PSEQ-2. J Pain. 2015;16:153-63. https://doi.org/10.1016/j.jpain.2014.11. 002.

33. Ferreira GE, Kamper SJ. Clinimetrics: the back beliefs questionnaire. J Physiother. 2020. https://doi.org/10.1016/j.jphys.2020.03.003.

34. Bandurra A. Self-efficacy: toward a unifying theory of behaviour change. Psychol Rev. 1977;84:191.

35. Team RC. R: A language and environment for statistical computing (Version 3.4. 2)[Computer software]. In: R: A language and environment for statistical computing. R Foundation for Statistical Computing. Vienna, Austria; 2012. http://www.r-project.org/.

36. Thorborg K, Hölmich P, Christensen R, Petersen J, Roos EM. The copenhagen hip and groin outcome score (HAGOS): development and validation according to the COSMIN checklist. Br J Sports Med. 2011;45:478-91.

37. de Vet HCW, Terwee CB, Mokkink LB, Knol DL. Measurement in medicine. Cambridge: Cambridge University Press; 2011

38. Cangur S, Ercan I. Comparison of model fit indices used in structural equation modeling under multivariate normality. J Mod Appl Stat Methods. 2015:14:152-67.

39. Hooper D, Coughlan J, Mullen M. Equation modelling: guidelines for determining model fit. Electron J Bus Res Methods. 2008;6:53-60.

40. DiStefano C, Liu J, Jiang N, Shi D. Examination of the weighted root mean square residual: Evidence for trustworthiness? Struct Equ Model. 2018;25:453-66. https://doi.org/10.1080/10705511.2017.1390394.

41. Cohen J. Statistical power analysis for the behavioral sciences. 2nd ed. Hilsdale: Lawrence Earlbaum Associates; 1988. 
42. Eisinga R, Te Grotenhuis M, Pelzer B. The reliability of a two-item scale: Pearson, Cronbach, or Spearman-Brown? Int J Public Health. 2013;58:637-42.

43. Koo TK, Li MY. A Guideline of selecting and reporting intraclass correlation coefficients for reliability research. J Chiropr Med. 2016;15:155-63. https://doi.org/10.1016/j.jcm.2016.02.012.

44. de Vet HCW, Terwee CB, Knol DL, Bouter LM. When to use agreement versus reliability measures. J Clin Epidemiol. 2006;59:1033-9.

45. Terwee CB, Bot SDM, de Boer MR, van der Windt DAWM, Knol DL, Dekker $J$, et al. Quality criteria were proposed for measurement properties of health status questionnaires. J Clin Epidemiol. 2007;60:34-42.

46. Jakobsen JC, Gluud C, Wetterslev J, Winkel P. When and how should multiple imputation be used for handling missing data in randomised clinical trials - a practical guide with flowcharts. BMC Med Res Methodol. 2017:17:1-10.

47. Hall AM, Aubrey-Bassler K, Thorne B, Maher CG. Do not routinely offer imaging for uncomplicated low back pain. BMJ. 2021;372:1-7.

48. O'Hagan ET, Di Pietro F, Traeger AC, Cashin AG, Hodges PW, Wand BM, et al. What messages predict intention to self-manage low back pain? A study of attitudes towards patient education. Pain. 2021. https://doi.org/ 10.1097/j.pain.0000000000002530.

49. Nielsen AM, Hartvigsen J, Kongsted A, Öberg B, Enthoven P, Abbott $A$, et al. The patient enablement instrument for back pain: reliability, content validity, construct validity and responsiveness. Health Qual Life Outcomes. 2021;19:1-14. https://doi.org/10.1186/s12955-021-01758-0.

50. Ajzen I. The theory of planned behavior. In: Van Lange P, Kruglanski A, Higgins E, editors. Handbook of theories of social psychology, vol. 1. London: Sage; 2001. p. 438-59.

51. Carrozzino D, Patierno C, Guidi J, Berrocal Montiel C, Cao J, Charlson $\mathrm{ME}$, et al. Clinimetric criteria for patient-reported outcome measures. Psychother Psychosom. 2021;90:222-32.

\section{Publisher's Note}

Springer Nature remains neutral with regard to jurisdictional claims in published maps and institutional affiliations.

- fast, convenient online submission

- thorough peer review by experienced researchers in your field

- rapid publication on acceptance

- support for research data, including large and complex data types

- gold Open Access which fosters wider collaboration and increased citations

- maximum visibility for your research: over 100M website views per year

At BMC, research is always in progress.

Learn more biomedcentral.com/submissions 